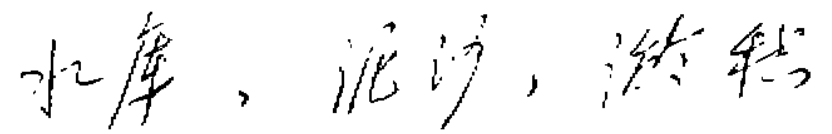

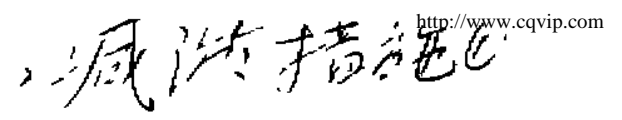

第, 0 类管 1 期

湖

泊 科

学

Vol. צ. Niיl Jo )URNAL, ()F L.AKE, SCIENCES

Mar. , 1997

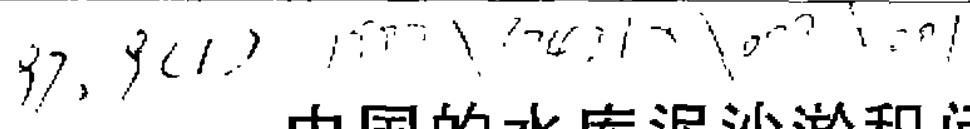 \\ $1-8$ \\ 中国的水库泥沙淤积问题

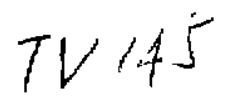

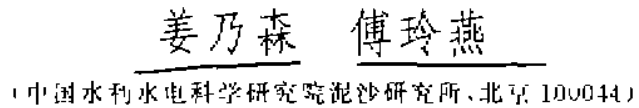

\section{提要}

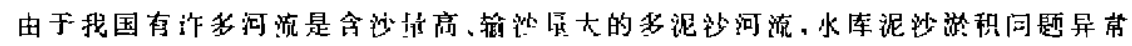

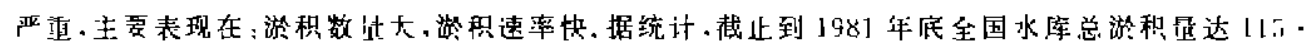

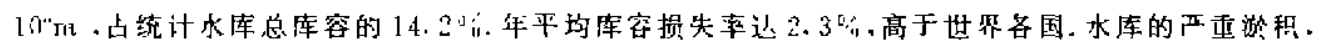

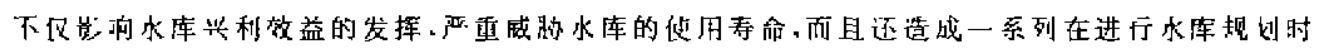
未曾充分估计到的环境问题. 本文重点从河流水文现沙特性、我国水库淤积问题的严重沚、水卢淤

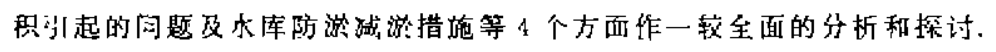

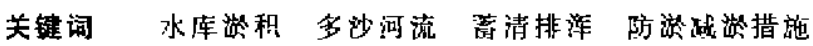

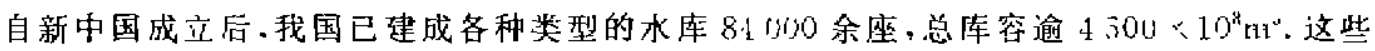
工程对促进我国的工农业发展起了很大作用。然而，由于有许多河流是含沙量高、输沙量大的 多泥沙河流・水库建战蓄水后, 淤积问题异常产重.这不仅直接影响着水库兴利效益的发挥, 而 且还为社会环境带来一系列问题. 为此、水库泥沙淤积问题一直受到有类部门和科技工. 作者的 重视. 早在60年代初、水电部就曾确定官厅、三门崦等 12 座水库为开展水库泥沙观测研究的 重点水库.70年代又成立过“全国重点水伡水文泥沙观测研究协作组”. 经过30余年的努力. 不仅积累了丰富的实河资料，提高了处理水库㳸沙问题的技术水平。而且通过室内试些研究， 对水库泥沙运行规律、水库防淤、减淤措施等都有了较深刻的认识. 目前、一些研究成果和防淤 减淤措施已为广大设计和水库管理人员所接受并付诸实践.对减缓我国的水库湤积状况,发挥 水库综合利用效益起到积扱作用。

\section{1 河流含沙量高、输沙墨大}

我国有许多河流，特别是北方河流大都发源或流经黄土地区、而这些地区地表植被覆盖 少、汛期多暴雨. 水上流失严重.河流的含沙童都很滈. 丛中外主要河流泥沙量的对比 ${ }^{14}$ - 来看、 我国河流含沙童之高、铪沙量之地地世界之冠。

\section{2 水沙量在年内的分配极不均匀}

由于我国北方地区冬春季干早少雨。雨量主婜集中于汛期・且多暴雨・故河流的水、沙量主 要集中于汛期，从部分多沙河流水库汗期人库水沙量占全年总量的百分比来看·北方河流汛期

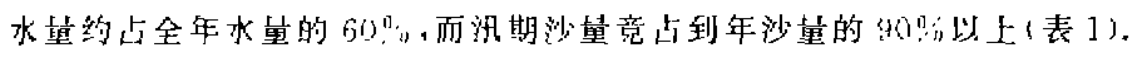

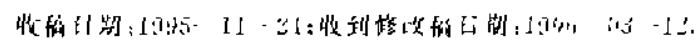

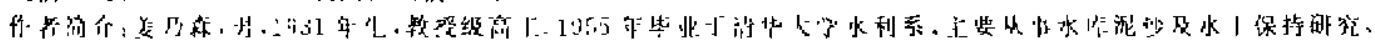

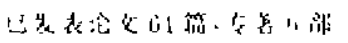




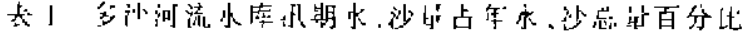

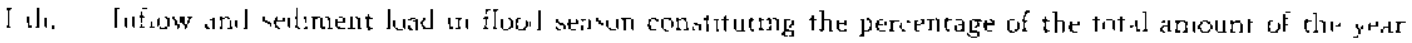

\begin{tabular}{|c|c|c|c|c|c|c|c|c|c|}
\hline 小" & 训安如! & I小晾 & 45 & 阳点行 & 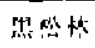 & 和5架 & 证: & 行山! & 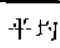 \\
\hline ل & $\therefore$ & $! !$ & $5 \overline{2} 9$ & : & i5 & $+7 . \ddot{a}$ & bil & 73 & F 2 \\
\hline 小男。”。 & $\ldots$ & il & 15.7 & re & $9 \mathrm{~A}$ & $y 7$ & 96 & 85 & 4.8 \\
\hline
\end{tabular}

2 渓积问题的严重性

2. 1 於积数量大

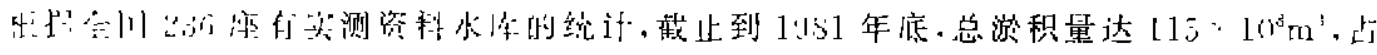

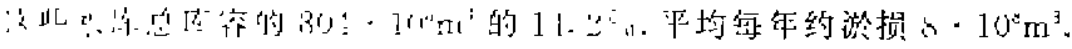

\section{2 淤积速率栱}

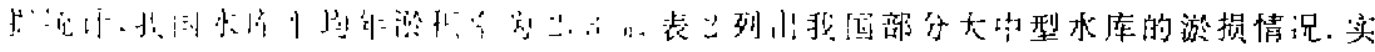

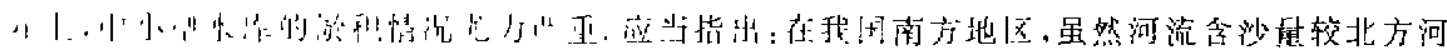

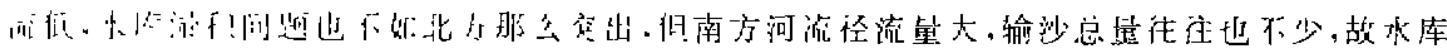

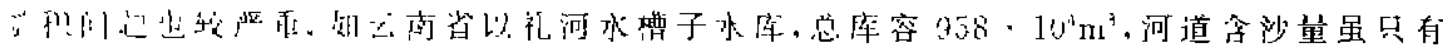

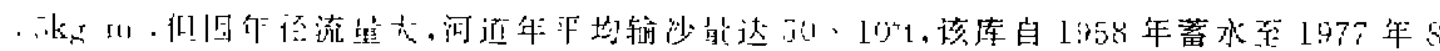

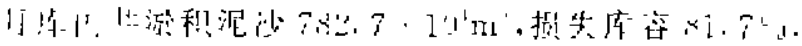

\section{3 水振淤积引起的问题}

\section{I库容减少、水库兴利效益降低}

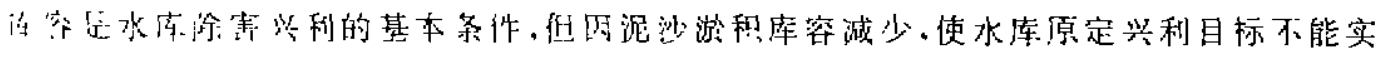

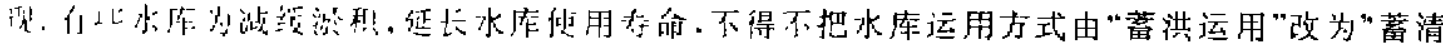

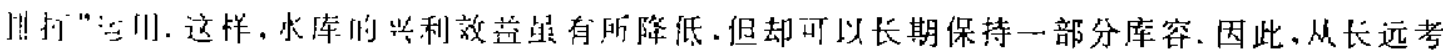

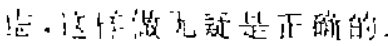

\section{2 水库淤积末端向上游延伸.造成回水末端地区淹没、浸没损失扩大}

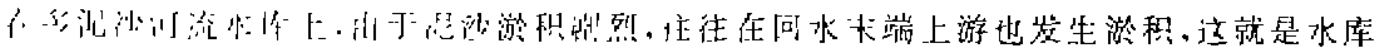

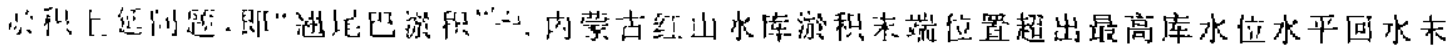

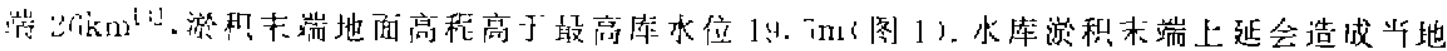

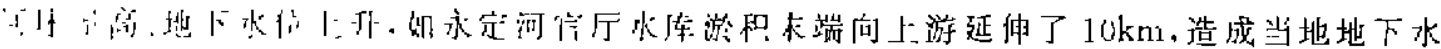

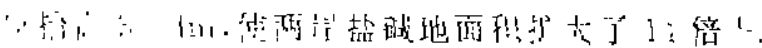

\section{3 污染水质}

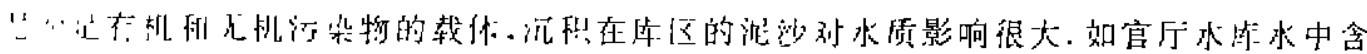

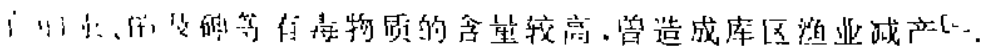

\section{: 十盟隄航运}

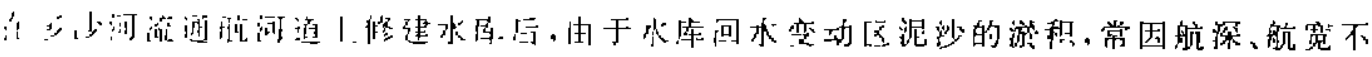

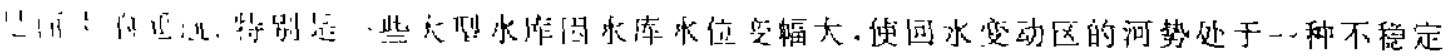

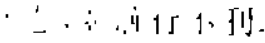


表 2 部分水库库容淤损情况

Tab. : Sedimentettion in some reservolru in china

\begin{tabular}{|c|c|c|c|c|c|c|c|c|}
\hline \multirow{2}{*}{ (4) } & \multirow{2}{*}{$\begin{array}{l}\text { 水㤽 } \\
\text { 维称 }\end{array}$} & \multirow{2}{*}{ 讷梳 } & \multirow{2}{*}{ 考小《人 } & \multirow{2}{*}{ 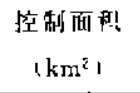 } & \multirow{2}{*}{$\begin{array}{l}\text { 初始㪀容 } \\
\left.1 \cdot 10^{4} \mathrm{~m}^{\circ}\right)\end{array}$} & \multicolumn{2}{|c|}{ 总漰和量 } & \multirow{2}{*}{$\begin{array}{l}\text { 统计 } \\
\text { 年份 }\end{array}$} \\
\hline & & & & & & 总量，人 $111^{A} \mathrm{~m}^{3}$ ) & 占总伡荌( 唋) & \\
\hline . & $=1 ! k$ & 黄河 & 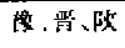 & $68 \times 490$ & 96.4 & 56.9 & 58.1 & $19441 \quad 1489$ \\
\hline 2 & 号旧 & 老债河 & 内蒙 & 24456 & 25.6 & 6.7 & 26 & $1960--J 4 \times 7$ \\
\hline 3 & 勈门 & 水定河 & 北京 & 47600 & 23.7 & 6. .5 & 27.8 & $1.353^{-}-\mathrm{J} 494$ \\
\hline 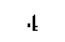 & 被叮 & 济测 & 山西 & $5 \div 68$ & 7.21 & 3.31 & 45.9 & $1960-1989$ \\
\hline 3 & 测察财 & 告河 & 甘林 & 17213113 & 57.2 & 11.1 & 21.7 & $1968-1989$ \\
\hline 6 & 扑江山 & 攺部。 & 潮北 & $95 \div 17$ & $16: 1$ & 11.3 & 7.1 & $1968-1485$ \\
\hline 7 & 闺消 & 激沱河 & 河北 & I5960 & 15.58 & 2.35 & 15.1 & 191002970 \\
\hline 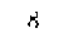 & 都 & 干河 & 山西 & 16900 & 3.0 & 3.05 & 102.5 & $1960--2983$ \\
\hline$;$ & 张家漓 & 清水河 & 讪页 & 813013 & 1. 19 & 1. $11 !$ & di. 5 & $1959-: 951$ \\
\hline 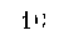 & 颎子梁 & 深诃 & 山西 & 1810 & 0. 36 & 0. 29 & 80 & $1059-2 \div 73$ \\
\hline 11 & 间蚛游 & 柳诃 & i工宁 & 1501 & 1.68 & 0.02 & 1 & $1963--1986$ \\
\hline L' & 俈吗 & 大漳河 & 四川 & $76401)$ & 3. 57 & 2. 06 & 80.1 & $19157 \quad 1987$ \\
\hline $1 j$ & 菂口 & !'龙江 & 比林 & 27600 & 5.21 & 2. 18 & 11.8 & $1976-1986$ \\
\hline $1 t$ & 结 & 俈和 & 跃西 & 3861 & 1.45 & 0.28 & 25.8 & $1973--: 585$ \\
\hline $1 ;$ & 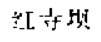 & 嫁本 & 炢陌 & 121.3 & (1. 3.4 & 0. 117 & 19.2 & $19150--2986$ \\
\hline 15 & 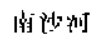 & 自䏚河 & 频西 & 243.5 & (1. $2 \mathrm{~J}$ & 0.03 & 15 & $1960 \bar{u}-2.988$ \\
\hline 17 & 土. & 惁子河 & 非咽 & $321 \%$ & 2.813 & 11. 77 & 37.9 & $1972-1990$ \\
\hline lr & 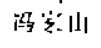 & 干河 & 陈曲 & 123 & 3.89 & (1. 63 & 16 & $1971 \quad 19901$ \\
\hline$t^{\prime i}$ & 长䄸 & 矤本 & $8 \Gamma \bar{T}$ & 848.5 & 3. 57 & 0.04 & 1.2 & $1970-1981$ \\
\hline$s$ & 洴源 & 弥河 & 山东 & 789 & 1. & 0.12 & 7.8 & $1955-1981$ \\
\hline$? !$ & 青锋峂 & 深矿 & 山东 & Fili & 1. 2.4 & a 10 & 3. 8 & $1900-1981$ \\
\hline 22 & 纱山 & ґ果词 & 湖北 & $18:$ & 1.69 & 0. 12 & 1.7 & $1959-1981$ \\
\hline $3 j$ & 白连测 & 泽水 & 湖北 & $18 \mid 11\}$ & 12.5 & (1. 21 & 7.1 & $1960--1,381$ \\
\hline 3 & 革底滩 & 堵阿 & 湖北 & $1111 \%$ & 1.11 & 11. 2 & 20 & $197 z-1980$ \\
\hline ויזירי & 上阮让 & $\mathrm{t}=1$ & 江㟧 & $=750$ & 7.2 & 0.09 & 1.2 & $1957-1982$ \\
\hline $3 i$ & 仙售 & 性逊词 & 洞北 & $\because 400$ & 1.83 & 0.47 & 53 & 196013989 \\
\hline $2 \hat{i}$ & ll & 疑河 & 河南 & $98 \overline{5}$ & 245 & n. 22 & 7.5 & $1953 \quad ! 381$ \\
\hline 28 & 比趾 & 群汇 & $r^{-}$两 & 77311 & 14 & i1. 67 & 4.8 & $19 \pi 4-1379$ \\
\hline $2 ! !$ & 东业 & 諵阿 & 甘讨 & 552 & 6.77 & u. 11 & 53.7 & $1959-1983$ \\
\hline $3: 1$ & 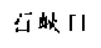 & 沙水河 & 部政 & 3 8it8 & 1.35 & 0.35 & 20 & $1959 \quad 1988$ \\
\hline$\therefore 1$ & 长川\% & 浦木河 & 第罂 & $2+174$ & 3.18 & 0.17 & $1 s .5$ & $1960-1386$ \\
\hline$\because:$ & 定峈河 & 文峈社 & 敞此 & 1870 & 1175 & 2. 20 & 19 & 195,91988 \\
\hline $3 \div$ & 巴家叫l & 泝汕 & 甘淋 & $35: 2$ & 4. 40 & :. 14 & $50 .:$ & $1958-1990$ \\
\hline il & 芹电济 & 洲 inj & 阦些 & 1 & $1 ?$ & 1). 17 & 1.1 & $1970-1990$ \\
\hline$i \xi$ & ț & 悹次河 & 阿鲇 & $9<13$ & 1.45 & 0.08 & 1 & $10717 \quad 1991$ \\
\hline $3 !$ & 屾檌 & 你浲测 & 屾南 & $31: 2$ & 13.? & 1). 6.2 & 4.7 & $1950-1983$ \\
\hline
\end{tabular}

\section{5 坝区泥沙淤积}

坝区泥沙游积是指大坝或枢纽工程附近河段的淤积,包括电站进水口、上下游引航道及船 闸闸室的淤积等。坝前泥沙淤积有可能堵塞闸孔，威胁工程安全. 此外、从水库排出的淤沙颗粒 较粗.从而加重了泥沙对泄流建筑物及水轮机过流部件的磨蚀.

3.6 对水下游河道的影响

任多湤河流上修建水库后, 政变了水库下游河道自然的来水来沙条件, 下游河道的沖淤直 


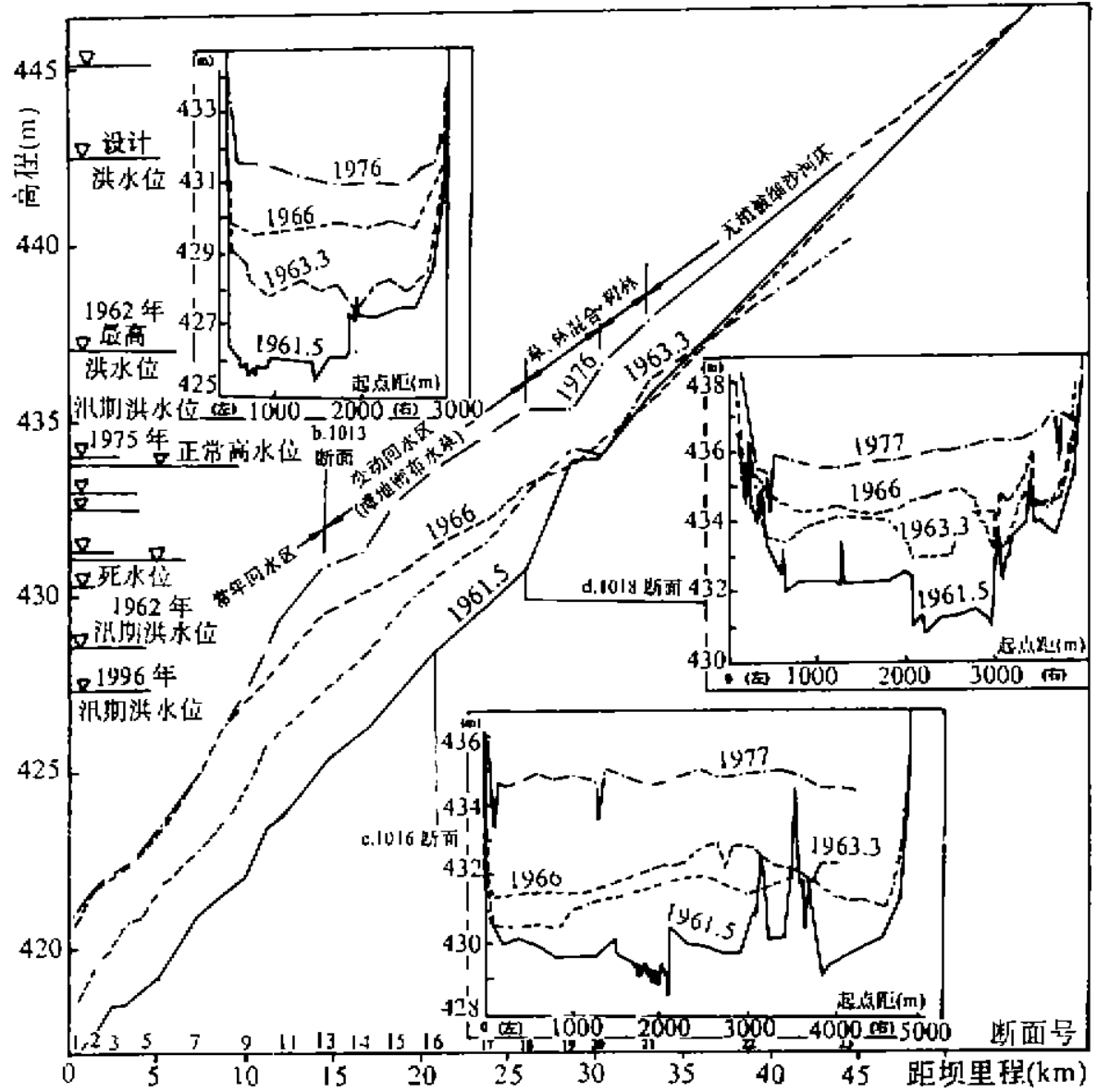

图 I 红山水伡河床最低点新剖而

Fig. 1 Longirudinal profile of sedimentarıon for Hongshan Reservor

接受水库调节的影响.一般蓄洪运用水库,库区泥沙淤积,出库为清水. 清水会使下游河道发生 长距离冲刷，如三门峡水库建成初期下游河道发生冲刷，造成滩地的大紫均塌并使险情增加。 三门峡水库在改变运用方式为“蓄清排浑”后, 常因水库泄流能力不足面发生滞洪淤积, 出库浑 水常发生“大水带小沙、小水带火沙”的不协调局面，造成下游河槽的淤积,对防洪极为不利. 因 此,迫使该库进行工程改建,改建后工程泄流能力加大,使一般洪水不再发生滞洪,出库水沙过 程地比较适应了。才使库区及下游河道的不利局面有所改善,

\section{4 水库防淤減淤措施}

\section{1 上游拦蓄、减少入库沙量}

防止或城缓水库淤积的根本措施是减少人库沙量. 实践证明、对于流域面积不太大的大中 型水库来说、流域的综合治理，在短期内对人库沙望就可起到明显的减少作用. 如红山水库 ${ }^{5}$, 60 年代和 70 年代比、水库上游流域的年均降雨量均接近多年平均值 $463.3 \mathrm{~mm}$, 但输沙量却相

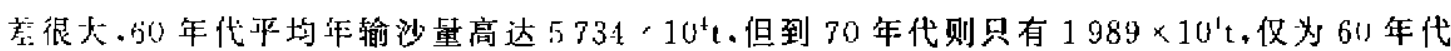


的 $35 \%$. 该流域来沙量大幅度减少的主要原因就是上游水利、水保工程的拦测; 作用。6以年代至 70 年代中期, 流域灌渴面积和水库库容增加较多,而且在整溉面积中大部分出引洪淤濩,故拦 沙效益显著(图 2). 永定河官厅水库也有类似情况.

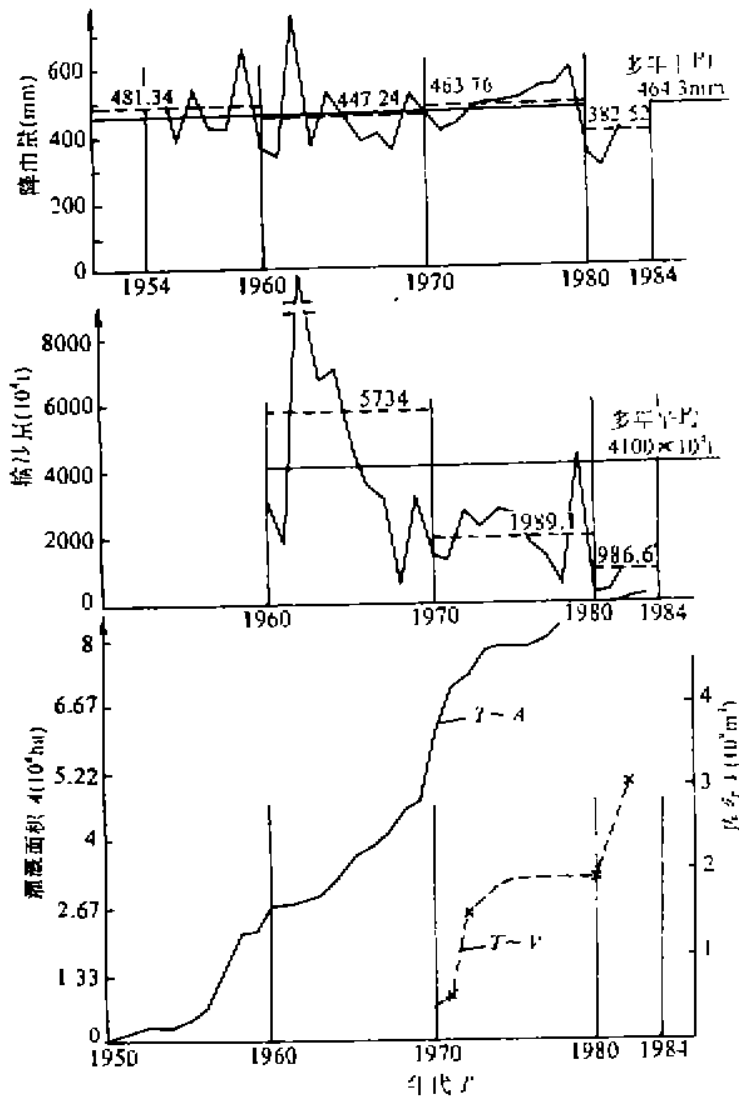

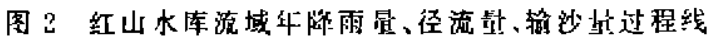

Fig. 2 Coorlmated hydrographs for the tuasin of Hongshan Rekervor

\section{2 优化规划设计}

中国水库淤积问题之所以如此严重，不少是在规划设计时对泥沙问题估计下足所㳩。尤其 是在建国初期修建的一些水库更是如此，实践证明.多沙河流规邚水库时。不能只考虑彺流调 节, 还须考虑泥沙调节。

衡星水库淤积是否严重的一个指标，就是前述的水伡平均年淤积率 $R_{\mathrm{r}}$ ～$R$ 、与水库的运用 方式、年人库沙舅的多赛及原始库容的大小等因素有关. 根据我国部分蓄洪运用水库的资料分 析可得如下关系式-20(图 3);

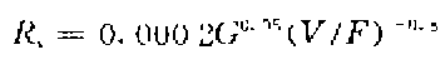

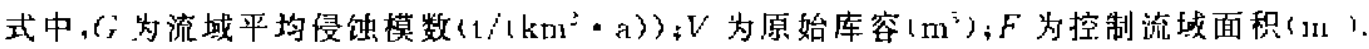

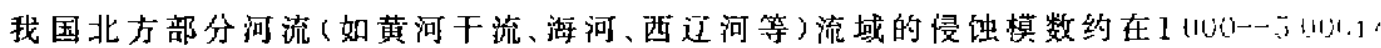




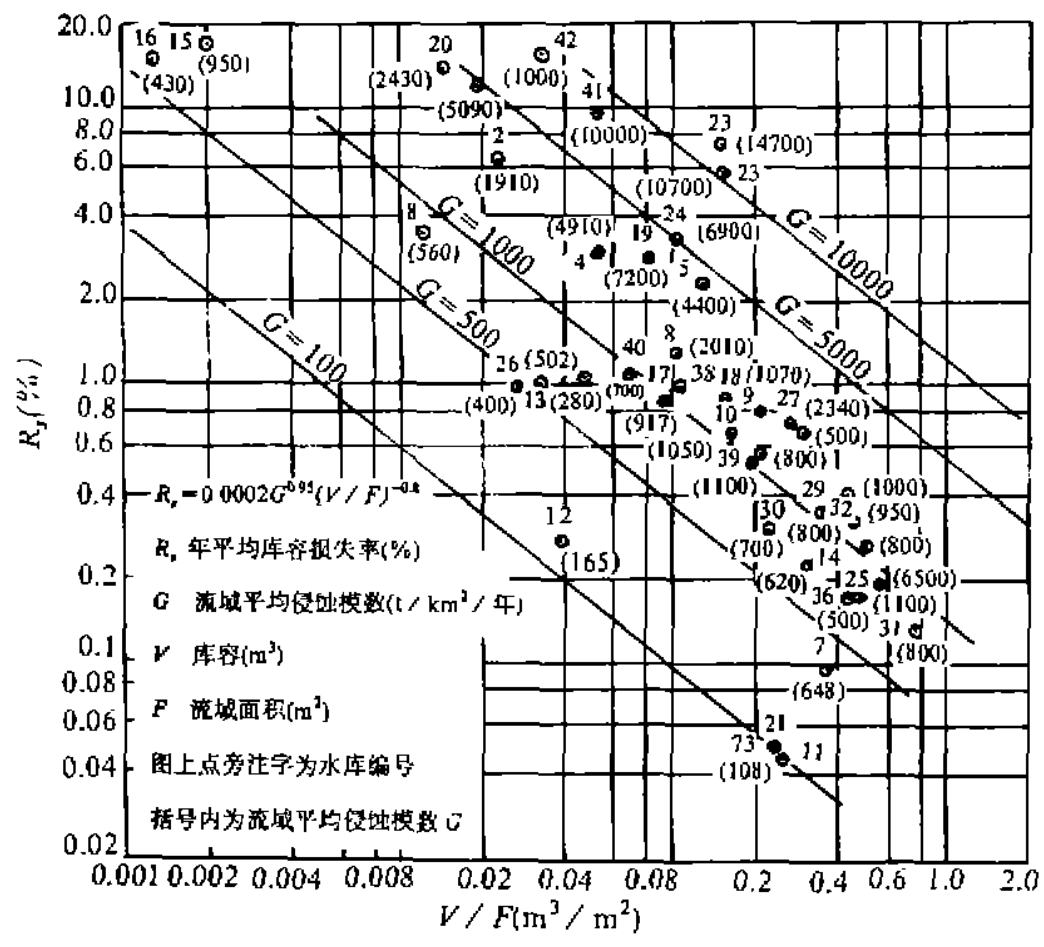

图3望水运用水库平均库容揭失率与水库及流域特性关系

Fig. 3 Relationshıp between the lost rate of the storage capacity and the characteristics of the recervour

$\left(\mathrm{km}^{2} \cdot \mathrm{a}\right)$. 在这些河流上修建水库, 应考虑参数 $V / F . V / F$ 值愈大.水库的相对库容较大.使用 年限愈长. 从图 3 可看出, 平均情况下, $V / F$ 值不宜小于 $0.1 \mathrm{~m}^{\mathrm{s}} / \mathrm{m}^{2}$, 否则水库的平均年淤积率

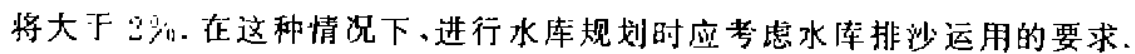

为有利于排沙运用, 要设置高程较低, 泄量较大的泄流排沙建筑物 (如排沙底孔或排沙洞) 以达到调沙的目的. 如三门峡水库由于泥沙游积严重,在 1962 年就改蓄水运用为蓄清排浑运 用. 但由于原有泄水建筑物泄量不够大,高程又较高、故遇较大洪水时(如 1964 年), 库内仍壅 水较高、淤积仍很严重.迫使水库改建. 改建后增大了水库的泄流规模、降低了坝前侵诎基面、 才缓解了水库严重游积的局面 ${ }^{[\mathrm{p}]}$.

\section{3 合理的水库运用方式}

多沙河流水库选择一个合理的运用方式并精心调度运用水库、对減缓水库游积、发挥水库 效益有着极为重要的作用. 我国曾有不少水库在建库初期来取蓄洪运用方式,后因水库淤积严 重才被迫改为蓄清排浑运用. 当然、蓄清排浑运用因汛期需泄水冲沙, 必然对发电等综合利用 效益有影响，但这样却能较长期地保持部分库容进行水沙调节、除害兴利.

衣 3 列出了部分水库平均年库容损失率与相对库容特征值 $C<$ 河流年沙童与原始总库容 之比; 的对照关系. 大致可以认为: 当 $C$ 值在 $0.01-0.05$ 时, 水浑平均年库容损失率约为 $20 \%$ 左存. 因此. 在多沙河流上修建水库, 若 $($ 值大于 0.01 时. 就宜于采取蓄清排浑的运用方式. 
表 j

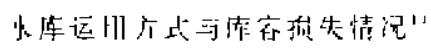

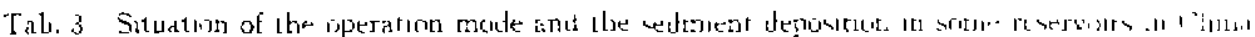

\begin{tabular}{|c|c|c|c|c|c|c|c|c|c|}
\hline , 5 & 床在 & 部话 & 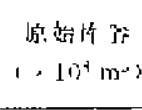 & 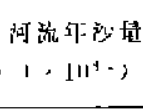 & 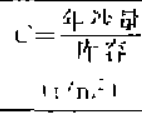 & 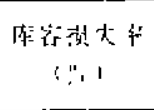 & 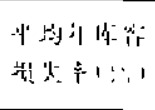 & 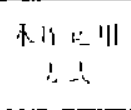 & $\begin{array}{c}.1 \text { i ! ! } \\
1 \text { ' }\end{array}$ \\
\hline \multirow[t]{2}{*}{. } & \multirow[t]{2}{*}{ 沁性 } & \multirow[t]{2}{*}{ 站顾 } & $26:$ & 16 & 110019 & 14.5 & 4.5 & 徣 & $\overline{5}$ \\
\hline & & & IB: & 10 & $\therefore .15 .5$ & 1 & 1.4 & 辛调 ll: 许 & $1=$ \\
\hline \multirow[t]{2}{*}{3} & \multirow[t]{2}{*}{ 瞋一千梁 } & \multirow[t]{2}{*}{ 深诃 } & 1) 36 & U. 1:y.t & $18.2 \pi$ & 36 & 12 & 筑荘。 & .' \\
\hline & & & $\therefore 36$ & (1, 1), & :1 20 & 35 & $1 \ddot{~}$ & 害治非河 & . \\
\hline \multirow[t]{2}{*}{$\because$} & \multirow[t]{2}{*}{ 墨松林 } & \multirow[t]{2}{*}{ 公蜼湴 } & 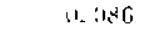 & 1. 0071 & 1. 1.83 & $2 \%:$ & 1. $\bar{i}$ & 恕拉 & $i$ \\
\hline & & & 11. 0813 & $\therefore 6071$ & 11.283 & 20. & 10. 7 & 简出排湔 & 3 \\
\hline \multirow[t]{2}{*}{4} & \multirow[t]{2}{*}{ 红领 I!I } & \multirow[t]{2}{*}{ 本縻问 } & 0.160 & 0.016 & 1I. $113 \hat{0}$ & 11 & $\therefore " 1$ & 莦浓 & ; \\
\hline & & & 0.266 & 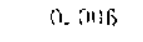 & 1. 035 & 11 & 2.9 & 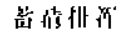 & י \\
\hline \multirow[t]{2}{*}{$\vdots$} & \multirow[t]{2}{*}{ 乐屼 } & \multirow[t]{2}{*}{ 南呵 } & $0 \overline{0} 37$ & (1. I12e & 0.067 & j.l. 1 & 3.9 & 音部 & 17 \\
\hline & & & 1.. 37 & 11. 025 & 11.115 .7 & 31.1 & s. ' & 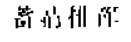 & 17 \\
\hline \multirow[t]{2}{*}{6} & \multirow[t]{2}{*}{ 烸形 } & \multirow[t]{2}{*}{ 丮余啝 } & 0.13 & 0.1113 & 0. $: 188$ & 7.5 & $\therefore \overline{7}$ & 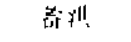 & : \\
\hline & & & 0.12 & ก. 01.3 & 0. 1118 & $\bar{i} . \overline{3}$ & $\therefore \mathrm{J}$ & 荒沙计游 & : \\
\hline
\end{tabular}

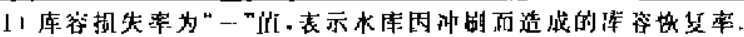

水库采取蓄清排浑运用方式,一般靠汛 期的冲刷都能把非汛期蓄水时游在库内的 泥沙冲出库, 即作到泥沙冲湤年平衙, 如三 门峡、黑松林等水库. 图 4 为三门峡水库 $330 \mathrm{~m}$ 高程以下库容的变化情况. 由图可 见,1464 年工程改建之前 $\mathrm{t}$ 由于治沙淤积优 库容急剧损失. 随着改建工程逐步完成, 汁 期发生冲别、库容不仅没有损失, 且略有恢 复.

另有某些水库(如山西省恒山水库辝) 采取泥沙多年调节的运用方式. 即一般年 份全年篦水兴利、使来沙中的绝大部分淤 在库内, 每隔 1 年左右进行一次汛期桜空 水库冲刷, 可把前期库内游沙冲刷出库, 达 到泥沙冲游多年平衡。

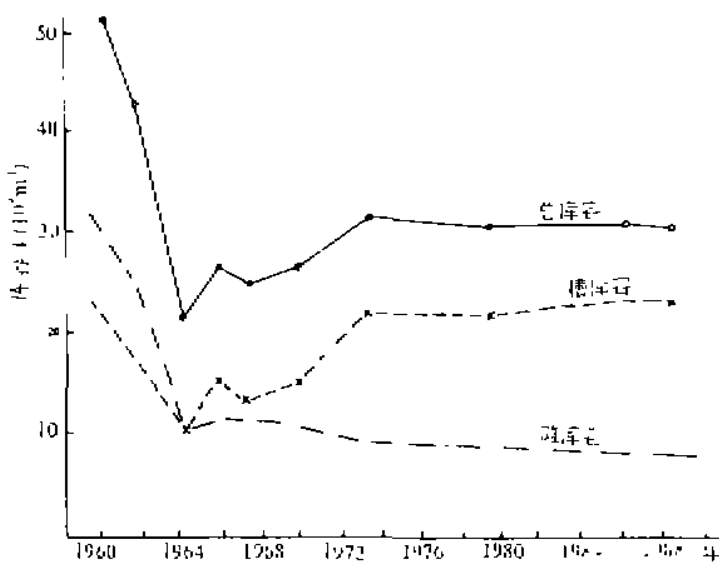

图: 三门峣水伡库容变化过拜

Fig. A Tempor.sl variation of siuras̆e cipacily im Samenxia Rewrever

\section{4 机械清游}

我国也有部分水库利用机械进行清 沵. 如利用挖泥船、气力原和水力吸㳸装置等. 机械清游的最大优点是不需耗费大量水量, 这对 我国北方干旱缺水地区存重要意义. 鉴于我国河流含沙量高、输沙量大,单靠挖沙侬复库容, 仆 于大中型水库来说是困难的. 此外, 机械挖泥耗资也较高.因此, 大型水轪很少采用这种办法.

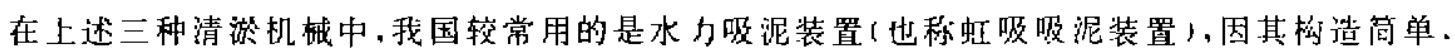
便于操作. 且排沙动力主要是依靠水库上下游水位差, 不需附加更多的动力, 故较经济. 


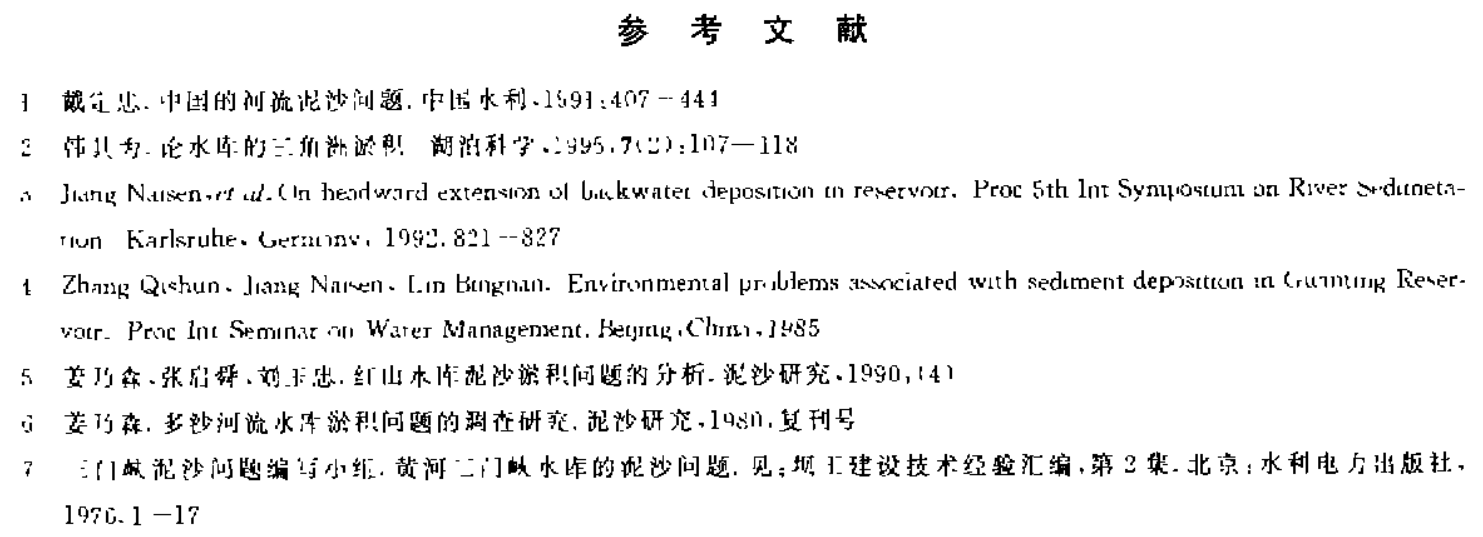

\title{
PROBLEMS OF RESERVOIR SEDIMENTATION IN CHINA
}

\author{
Jiang Naisen Fu L,ingyan

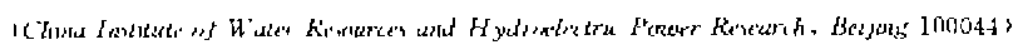

\begin{abstract}
There are miny heavily sediment-ladden rivers in Chma, with high sediment concentration and a large quantity of sediment load. The reservoir sedmentation problems in those rivers are so serrsus that the amount of scdiment deposited in the reserwoir is great and the rate of sedimentation ts accelerated. Aceordeng to the statistics, up to the end of 1981, it total amount of 11.5 . $10^{1 "} \mathrm{~m}$ ' if sediments were approximately accumulated in the reservoirs, and $14.2 \%$ of the design capacty was lost. The average annuil loss in capncity firr storage reservoirs reaches 2.3 pereent, the hryhest in the wirld.

Silting of mpounding lakes nnt only has an cllect on the benefits of the reservoirs and serisusly threatins the life of rescrvoirs, but also entails many environmental problems nol fully anticspated at the time of planninir of the reservoir, which calls for the Chinese setentific-technical persontel to pay high attention to and make grual efforts in research on the methods of minmizing sedmenı depositisn.

In this papur, the stluation of reservior depostton in China will be describud, Thu. main content is as follows; 1 ) the characterislics of hydrolugy and sediment of rivers: 2 ) the scrususness of reservoir sedancntatuon in (hina: 3 t problems ciused by reservoir deposition; 1) the methods of mıninizıng sediment depisstion cte.
\end{abstract}

Key Words Rescrunir scdmentanon. ryers wilh heavy sedinent load. impounding clear water and relenstng mudly water, measure of muninizing sediment depostion 